\title{
Dental caries trends among preschool children in Indaiatuba, SP, Brazil
}

\author{
Regiane Cristina do Amaral', Marília Jesus Batista'1, Maria Paula Maciel Rando Meirelles', \\ Silvia Cypriano ${ }^{2}$, Maria da Luz Rosário de Sousa ${ }^{1}$
}

1 Universidade Estadual de Campinas - UNICAMP, Piracicaba Dental School, Department of Community and Preventive Dentistry, Piracicaba, SP, Brasil

${ }^{2}$ Pontíficia Universidade Católica de Campinas - PUCCAMP, Dental School, Department of Community and Preventive Dentistry, Campinas, SP, Brasil

\begin{abstract}
Aim: To evaluate caries experience and associated factors in 5-year-old preschool children in the city of Indaiatuba, SP, Brazil. Methods: This was a cross-sectional, representative study, conducted from an epidemiological oral health survey (2010) with 303 children. The sample was established by the systematic probabilistic method, in public and private schools, in accordance with WHO criteria. The sample was checked for caries experience (dmft) by four trained and calibrated dentists, reaching acceptable levels of agreement for data collection. Parents or guardians answered questions related to their education and monthly income, and the children answered questions related to dental care and pain. Descriptive and bivariate analyses of independent variables were performed. Variables with $p \leq 0.20$ were included in the model (Poisson regression analysis). Results: The sample consisted of 151 boys and 152 girls, with a mean dmft of 1.46 . The reasons for visiting a dentist due to pain or need for treatment were associated with $\mathrm{dmft}>0$ $(P R=3.76,95 \% \mathrm{Cl}=2.06-6.84)$ after adjustment of the regression model. Conclusions: Among the preschool children of this study, pain or need for treatment due to caries disease in the primary dentition and the reason to visit the dentist due pain emphasizing the importance of the professional not only in curative actions, but as a health promoter at the first contact with the child.
\end{abstract}

Keywords: oral health; epidemiology; dental caries; preschool.

\section{Introduction}

Several publications have shown declining trends in caries experience, thus many researchers studied the factors associated with this decline ${ }^{1-4}$. Among the studied factors are family income and mother's education level ${ }^{1-2}$.

According to the SB Brazil 2010 data, there was a 17\% reduction in the 'decayed' component of dmft index in 5-year-old children, with a decrease in the mean dmft value from 2.8 in 2003 to 2.3 in $2010^{5}$. Nevertheless, Brazil did not show a significant decline according to the WHO (2000) goals for primary dentition

Received for publication: November 25, 2013 Accepted: March 10, 2014

Correspondence to: Maria da Luz Rosário de Sousa Universidade Estadual de Campinas Faculdade de Odontologia de Piracicaba Avenida Limeira 901, CEP: 13414-903 Bairro Areão, Piracicaba, SP, Brasil Phone: +55 1921065364 E-mail: luzsousa@fop.unicamp.br (5 years), which established a minimum proportion of $50 \%$ of caries-free teeth ${ }^{6}$, and it is far from fulfilling the WHO goal for 2010 of $90 \%$ of 5- and 6-year-old children free of caries ${ }^{7}$.

The city of Indaiatuba, SP, Brazil, presents a 0.79 Human Development Index $(\mathrm{HDI})^{8}$, which is above the Brazilian national average. This HDI denotes a situation not usually observed in other Brazilian cities regarding health indicators. Dental caries is a multifactorial disease caused by oral bacteria mediated by dietary carbohydrates, but income and education, which are both considered on HDI determination, might have an influence on caries' etiological factors. 
Dental caries in the primary dentition is considered a predictor of the disease in adulthood. More than two surfaces with caries experience in primary second molars at 5 years of age may represent a clinically useful predictor for high risk at age $10^{\circ}$. Thus the knowledge of caries disease in the primary dentition is important to determine whether the oral environment will be favorable or not during eruption of the first permanent molars, which are often more susceptible to caries'.

The aim of this study was to evaluate caries experience (dmft) and associated factors in preschool children in the city of Indaiatuba, SP, Brazil.

\section{Material and methods}

\section{Study design}

This research was a cross-sectional study conducted in the city of Indaiatuba, SP, Brazil, in 2010. The city of Indaiatuba is located 112 kilometers from the city of São Paulo, in the southeastern region of Brazil, has about 201,619 inhabitants and a land area of $311 \mathrm{~km}^{2}$ (IBGE) ${ }^{10}$.

To calculate the sample size, it was used the average $\mathrm{dmft}$ value and standard deviation obtained in a previous study (SES) ${ }^{11}$, adopting criteria of the SB Brazil Project $2010^{5}$ resulting in 296 pupils with $95 \%$ confidence level, $20 \%$ precision and design effect (deff) 2, according to the formula used by the SB Brazil 2010. Twenty percent were added to the total number of volunteers, in order to compensate for losses and refusals, then were selected a sample size of 355 pupils. Systematic probabilistic sampling was used, adopting the sampling without replacement rule in order to be representative of the municipality. Sample selection occurred in two stages, with the first draw of 20 schools that were organized according to the number of pupils, and then the 3555 -year-old children were randomly selected.

\section{Ethical aspects}

This study began after approval was obtained from the Ethics Committee of Piracicaba School of Dentistry (No. 105/2010). Parents or guardians signed an informed consent form authorizing the enrollment and participation of their children in the study. Parents or guardians also participated in the study answering a questionnaire about their socioeconomic conditions.

\section{Clinical examination}

For the examinations, a team of 4 examiners (dentists) was calibrated in a $36-\mathrm{h}$ training procedure, divided between theoretical discussions and practical activities, simulating the different conditions and situations that dentists might face during the course of practical work. The percentage of inter-examiner agreement was $95 \%$ for caries experience (dmft) and intra-examiner agreement was 98 to $100 \%$. The codes and criteria used for determining the dmft, which measures dental caries experience, were in accordance with the current recommendations of the World Health Organization $(\mathrm{WHO})^{12}$. The children were examined under natural light, using dental mirror and CPI probe for epidemiological surveys (WHO) $)^{12}$.

\section{Questionnaire}

Parents or guardians answered questions related to their education, income, number of rooms in the residence and number of children. The Parents or guardians were asked whether they had ever been to the dentist; place of the demand for dental service; the reason for seeking care; and whether the children had missed school activities because of toothache.

\section{Data analysis}

Data were tabulated in the Excel program and the SPSS 17.0 (Statistical Package for the Social Sciences; SPSS Inc., Chicago, IL, USA) for statistical analysis the program was used.

The descriptive analysis of the conditions was evaluated considering the weight, i.e. the value of each school relative to the population of 5-year-old children in Indaiatuba. Later, these variables were grouped and dichotomized for statistical purposes according to the distribution of the sample.

The data were further dichotomized relative to the number of rooms in the house; how many people lived in the house; how many children in the family; type of school (private or public), father's years of education; mother's years of education; school absence because of pain; if the child has been to the dentist; place of the consultation; reason for consultation, family income, and whether the child had treatment needs with regard to the $\mathrm{dmft}$.

The outcome chosen for the study was the $\mathrm{dmft}=0$ and $\mathrm{dmft}>0$. Bivariate analyses were performed (Chi-square test) and the variables that showed statistical significance $(p<0.20)$ were included in the multivariate analyses and Poisson regression with robust variance $^{13}$.

\section{Results}

In 2010, 303 children, 5 years of age, attending public and private schools of Indaiatuba, SP were examined. Due the loss of the $15 \%$ the sample, the final numbers of volunteers was of 303 pupils. The sample consisted of 151 boys and 152 girls. Among the 303 children examined, $177(58.4 \%)$ had dmft $\equiv 0,25(8.2 \%), \mathrm{dmft}=1$ and 32 $(10.5 \%) \mathrm{dmft}=2$, with a mean $\mathrm{dmft}$ of 1.46 . As regards the $\mathrm{dmft}$ components, $56.8 \%$ of the teeth were decayed and $42.8 \%$ were restored (Table 1).

The variables with $p<0.20$ in the bivariate analyses were included in the regression model as follows: father's schooling, missing school due to pain, going to the dentist, reason for consultation and treatment needs. After adjusting the model, only the variables father's education, income and reason for consultation were maintained in the analysis.

The reason for consultation, toothache and treatment need was associated with the presence of dental caries (Table 2). 
Table 1. Factors associated with $\mathrm{dmft}$ according to bivariate analysis, Indaiatuba - SP, Brazil, 2010.

\begin{tabular}{|c|c|c|c|c|}
\hline Characteristics & $\mathrm{n}$ & $\mathrm{dmft}=0$ & $\mathrm{dmft}>0$ & $p$ \\
\hline \multicolumn{5}{|l|}{ Gender } \\
\hline Male & 151 & 87 & 64 & \\
\hline Female & 152 & 90 & 62 & 0.7 \\
\hline \multicolumn{5}{|l|}{ Responsible for supporting family } \\
\hline Father or mother & 86 & 46 & 40 & \\
\hline Father and mother & 130 & 81 & 49 & \\
\hline Other & 11 & 8 & 3 & 0.28 \\
\hline \multicolumn{5}{|l|}{ Residents in family } \\
\hline Up to 4 dwellers & 157 & 92 & 65 & \\
\hline 5 or more dwellers & 70 & 42 & 28 & 0.57 \\
\hline \multicolumn{5}{|l|}{ Number of children } \\
\hline Up to 2 children & 163 & 98 & 65 & \\
\hline 3 or more & 65 & 37 & 28 & 0.61 \\
\hline \multicolumn{5}{|l|}{ Number of rooms } \\
\hline Up to 2 rooms & 157 & 90 & 67 & \\
\hline 3 or more & 65 & 42 & 23 & 0.31 \\
\hline \multicolumn{5}{|l|}{ Father's schooling } \\
\hline until 8 years & 78 & 43 & 35 & \\
\hline 9 years or mores & 139 & 92 & 47 & 0.1 \\
\hline \multicolumn{5}{|l|}{ Mother's education } \\
\hline Up to 8 years & 76 & 46 & 30 & \\
\hline 9 years or more & 152 & 97 & 55 & 0.62 \\
\hline \multicolumn{5}{|c|}{ Absence from school due totoothache } \\
\hline no & 218 & 134 & 84 & \\
\hline yes & 9 & 1 & 8 & 0.04 \\
\hline \multicolumn{5}{|l|}{ Visit to dentist } \\
\hline yes & 153 & 85 & 68 & \\
\hline no & 71 & 46 & 25 & 0.1 \\
\hline \multicolumn{5}{|l|}{ Place of visit to dentist } \\
\hline Public health & 64 & 34 & 30 & \\
\hline others & 91 & 52 & 39 & 0.6 \\
\hline \multicolumn{5}{|l|}{ Reason for consultation } \\
\hline routine / maintenance & 81 & 62 & 19 & \\
\hline pain / dental caries / bleeding / other & 58 & 16 & 42 & $<0.0001$ \\
\hline \multicolumn{5}{|l|}{ Income } \\
\hline Up to 1500 reais & 103 & 58 & 45 & \\
\hline More than 1500 reais & 90 & 53 & 37 & 0.09 \\
\hline \multicolumn{5}{|l|}{ School type } \\
\hline public & 273 & 155 & 118 & \\
\hline private & 30 & 22 & 8 & 0.81 \\
\hline \multicolumn{5}{|l|}{ Need of treatment } \\
\hline Does not need treatment & 198 & 175 & 23 & \\
\hline Needs treatment & 105 & 2 & 103 & $<0.001$ \\
\hline
\end{tabular}

Table 2. Factors associated with caries prevalence in the city of IndaiatubaSP, Brazil, 2010.

\begin{tabular}{llllll}
\hline Father's schooling & & $p$ & $P R$ & $C l$ & $95 \%$ \\
& $\begin{array}{l}9 \text { years or }+ \\
\text { up to 8 years }\end{array}$ & 0.224 & 0.780 & 0.522 & 1.165 \\
Reason for consultation, & $\begin{array}{l}1 \\
\text { pain+ need } \\
\text { routine }\end{array}$ & 0.000 & $\begin{array}{l}3.762 \\
1\end{array}$ & 2.069 & 6.840 \\
\hline
\end{tabular}




\section{Discussion}

The city of Indaiatuba has a history of epidemiological surveys on dental caries dating back to 1992 and there has been a decline in caries experience since then. Regarding this decline, differences were observed between the $\mathrm{dmft}$ components; for example, in the present study, $56.8 \%$ of the teeth were decayed and $42.8 \%$ were filled, with a mean $\mathrm{dmft}$ of 1.46. In other words, there was higher prevalence of the filled component than was shown in the last survey conducted in 2004 in Indaiatuba, which consisted of approximately 12\% of $\operatorname{cases}^{14}$.

According to the WHO goals for the year 2000, $57.4 \%$ $(\mathrm{n}=358)^{13}$ in 2004 and $58.4 \%(\mathrm{n}=303)$ in 2010 of the preschool children examined in the city of Indaiatuba were free of dental caries. Thus, the city of Indaiatuba fits in with this goal, and so do other cities in Brazil, such as Paulínia, $\mathrm{SP}$ and Salvador, BA, which had a dmft $=0$ in $54 \%$ and $50.4 \%$ of the children in $2003^{15}$ and $2005^{16}$, respectively.

Although this fact seems promising, the WHO established goals for $90 \%$ of children aged 5 and 6 years old (WHO) to be free of dental caries in $2010^{7}$. However, even in developed countries as belonging to United Kingdon this goal does not seem to be feasible since as in the England, Wales and Scotland the number of children with $\mathrm{dmft}>0$ was $38 \%$, $52.8 \%, 46 \%$ and $39.4 \%$, respectively, which is below the target set for the year 2010. According to the authors, these values characterize the failure to obtain significant improvements in the presented rates, primarily due to vulnerable groups ${ }^{17}$. On the other hand, there are countries like Kosovo, where only $2.1 \%$ of children aged 6 years were caries-free, most probably due to dentistry that calls for intervention, with no preventive work being done, and children only seek dental treatment only when they feel pain ${ }^{18}$.

Indaiatuba presented low dmft in the study, and has an HDI index considered high (0.79), when compare with the others countries, according to $\mathrm{WHO}^{19}$. The city has favorable characteristics with regard to education and health programs, and the monthly income of the examined children's parents was considered high. However, as a factor associated with dental caries, the reason for seeking the dentist was found to be pain or need for treatment. The relationship between the absence and presence of caries had as an associate factor the reason for seeking the dentist. Patients with pain or treatment needs showed a 3.7 times higher demand for care than patients who sought the service routinely. Similar results were found in the city of Recife, PE, where demand of service for treatment was 4.8 times higher than for prevention ${ }^{4}$, i.e., the population tends to delay seeking dental treatment.

Socioeconomic status has been considered a determinant factor of the risk for caries. Low income may be associated with the level of education, the value attributed to health, lifestyle and access to information on health care. As a result, the family income may be an indirect factor for susceptibility to caries ${ }^{20}$. Thus, in spite of socioeconomic factors considered as predictors of caries distribution in schoolchildren ${ }^{20-21}$, in similar studies an association was found between socioeconomic factors and dental caries ${ }^{22-23}$, and such data were not found in the present study. A possible explanation is the fact that, in the present study, there were not many individuals with very low income and the dichotomized income data showed values higher than those of other studies $^{22-23}$.

The results are similar with respect to years of education of the mother (caregiver). Some authors define this criterion as an indicator of caries disease $e^{4,24}$, but in the present study this was only significant for the father's number of schooling years.

Other factors, such as number of rooms in the residence, type of school, number of persons residing at home and number of children were not statistically significant in this study. These results were similar to those found by Cortellazzi et al., $2008^{25}$, with regard to the number of people in the same household; however, there was difference in the type of school and dental fluorosis.

Epidemiological surveys are important tools to diagnose the oral health status of populations and should contribute to the planning of health services. It should be emphasized the importance of the continuity of the oral health programs that have been implemented in the city in order to change the paradigm of seeking the dentist only in case of pain into a model for health maintenance and adherence of parents.

For preschool children in the city of Indaiatuba, the factor associated with caries disease in the primary dentition was the reason to visit to the dentist due to pain or need for treatment, thus highlighting the importance of the dentist not only in curative actions, but also as health promoters at the first contact with the child.

\section{References}

1. Alcântara TL, Batista MJ, Gibilini C, Ferreira NP, Sousa MLR. Factors associated with oral health of preschool children placed in preventive educational program in Piracicaba/SP. RPG Rev Pos-Grad. 2011; 18 : 102-7.

2. da Silva AN, Mendonça MH, Vettore MV. The association between low socioeconomic status mother's Sense of Coherence and their child's utilization of dental care. Community Dent Oral Epidemiol. 2011; 39: 115-26.

3. Cypriano S, Hugo FN, Sciamerelli MC, Torres LHN, Sousa MLR, Wada RS. Factors associated with the incidence of dental caries among schoolchildren living in a municipality with low prevalence of dental caries. Cienc Saude Colet. 2011; 16: 4095-106.

4. Melo MM, Souza WV, Lima ML, Braga C. Factors associated with dental caries in preschoolers in Recife, Pernambuco State, Brazil. Cad Saude Publica. 2011; 27: 471-85.

5. Brazil. Ministry of Health. SB Brazil. National Survey of Oral Health: 2010. Main results. Brasilia: Ministry of Health; 2011 [cited 2012 Jan 26]. Available from: http://189.28.128.100/dab/docs/geral/ projeto_sb2010_relatorio_final.pdf.

6. Lucas SD, Portela MC, Mendonça LL. Variations in tooth decay rates among children 5 and 12 years old in Minas Gerais, Brazil. Cad Saude Publica. 2005; 21: 55-63.

7. Pan American Health - Brazil [internet]. [cited 2014 Mar 10]. Available from: http://www.paho.org/bra. 
11. Secretary of State for Health (SEH). Regional Directorate of Health of Campinas. Epidemiological survey on oral health: the state of São PauloCampinas DIR XII; 1998. [Report presented at the conclusion of the research project conducted by the Center for Studies and Research in Health Systems, School of Public Health, University of São Paulo; 1999].

12. World Health Organization. Oral health surveys, basic methods. 4th ed. Geneva: WHO; 1997.

13. Moraes JFD, Souza VBA. Factors associated with the successful aging of the socially-active elderly in the metropolitan region of Porto Alegre. Rev Bras Psiquiatr. 2005; 27: 302-8.

14. Rihs LB, Sousa MLR, Cypriano S, Abdalla NM. Inequalities in distribution of dental caries in teenagers of Indaiatuba, São Paulo State, 2004. Cienc Saude Colet. 2010; 15: 2173-80.

15. Gomes PR, Costa SC, Cypriano S, Sousa MLR. Dental caries in Paulínia, São Paulo State, Brazil, and WHO goals for 2000 and 2010. Cad Saude Publica. 2004; 20: 866-70.

16. Almeida TF, Cangussu MCT, Chaves SCL, Castro e Silva DI. The dental health of preschool-aged children resident in areas covered by the Family Health Program, in the city of Salvador, in the State of Bahia, Brazil. Rev Bras Saude Matern Infant. 2009; 9: 247-52.

17. Pitts NB, Boyles J, Nugent ZJ, Thomas N, Pine CM. The dental caries experience of 5-year-old children in Great Britain (2005/6). Surveys coordinated by the British Association for the Study of Community Dentistry. Community Dent Health. 2007; 24: 59-63.

18. Begat A, Mega K, Siegenthaler D, Bearish M, Match W. Dental Health Evaluation of children in Kosovo. Eur J Dent. 2011; 5: 32-9.

19. Wikipédia. Annex: List of countries by Human Development Index [internet]. [cited 2014 Jan 24]. Available from: http://pt.wikipedia.org/wiki/ Anexo:Lista_de_países_por_índice_de_Desenvolvimento_Humano\# Desenvolvimento_humano_muito_alto

20. Solidário DMP, Holding JF, Moreira D, Rodrigues, JAO, Berilo MFG, Rosa EAR. Dental caries status in deciduous and permanent dentition of Brazilian children aged 6-8 years with a socio-economic base. Braz J Oral Sci. 2003; 2: 147-50.

21. Piovesan C, Mendes FM, Antunes JLF, Ardenghi TM. Inequalities in the distribution of dental caries among 12-year-old Brazilian schoolchildren. Braz Oral Res. 2011; 25: 69-75.

22. Pereira SM, Tagliaferro EP, Ambrosano GM, Cortellazzi KL, Meneghim M de C, Pereira AC. Dental caries in 12year old schoolchildren and its relationship with socioeconomic and behavioral variables. Oral Health Prev Dent. 2007; 5: 299-306.

23. Catani DB, Cypriano S, Sousa MLR. Clinical and socio-behavioral determining factors of dental caries in deciduous and permanent dentitions in a city with optimal fluoride concentrations in the water supply. Arq Odontol. 2010; 46: 197-207.

24. Tagliaferro EPS, Ambrosano GLB, Meneghin MC, Pereira AC. Risk indicators and risk predictors of dental caries in schoolchildren. JAppl Oral Sci. 2008; 16: 408-13.

25. Cortellazzi KL, Pereira SM, Tagliaferro EP, Tengan C, Ambrosano GM, Meneghim $\mathrm{M}$ de $\mathrm{C}$, et al. Risk indicators of dental caries in 5 year old Brazilian children.Community Dent Health. 2008; 25: 253-6. 